\title{
AN IMPLANTABLE PRESSURE SENSOR CUFF FOR TONOMETRIC BLOOD PRESSURE MEASUREMENT
}

\author{
Babak Ziaie, Tzu-Wen Wu, Namik Kocaman, Khalil Najafi, and David J. Anderson \\ Center for Integrated Sensors and Circuits \\ Department of Electrical Engineering and Computer Science \\ University of Michigan, 1301 Beal Avenue, Ann Arbor, Michigan 48109-2122 \\ e-mail: babak@engin.umich.edu, Tel: (734) 936-1413, Fax: (734) 647-1781
}

\begin{abstract}
This paper presents an implantable capacitive pressure sensor cuff for tonometric blood pressure measurement in unrestrained animals. A new structure and fabrication process have been developed which produce a flat surface necessary for tonometric pressure measurement. An array of three capacitive sensors is used to increase signal output and improve stability. A custom switched-capacitor CMOS interface circuit is used to measure changes in capacitance. In-vitro calibration tests have been performed on the complete cuff using a fluid-filled silastic tube to mimic a pliable blood vessel. A sensitivity of $2 \mathrm{mV} / \mathrm{mmHg} @ 100 \mathrm{mmHg}$ and a resolution of $0.5 \mathrm{mmHg}$ (based on $1 \mathrm{mV}$ RMS interface chip noise floor) has been obtained. The cuff system measures $10 \mathrm{~mm} \times 6.5 \mathrm{~mm} \times 3 \mathrm{~mm}$.
\end{abstract}

\section{INTRODUCTION}

Chronic measurement of arterial blood pressure in small mammals is a cornerstone of basic research in hypertension and cardiovascular physiology [1]. Long-term baseline stability has been a major requirement, and still poses many challenges to the successful deployment of implantable pressure sensors. Most available implantable sensors are piezoresistive devices (e.g., Data Sciences International, Roseville, Minnesota, and Konigsberg Instruments Inc., Pasadena, California), and either penetrate the vessel (Konigsberg), or connect to the vessel via an indwelling catheter (Data Sciences Int.). Both methods are very invasive and carry the risk of creating blood clots. These sensors have a long-term baseline drift of $>5 \mathrm{mmHg} / \mathrm{month}$ $[2,3]$ which is excessive for applications in low pressure systems (e.g., venous and urogenital system) or experiments that require a few months of continuos monitoring. To overcome these shortcomings, we have developed a miniature capacitive pressure sensor cuff for tonometric blood pressure measurement $[4,5]$. Capacitive sensors have high sensitivity, low power consumption, and are less prone to package stress which is the main source of baseline drift [6]. This paper reports a new sensor structure based on the dissolved-wafer process, which produces a flat surface necessary for tonometric pressure measurement, and presents the development of a complete system consisting of a custom switched-capacitor CMOS interface circuit for sensor readout, as well as a custom designed package for use in eventual animal studies.

\section{TONOMETRIC MEASUREMENT PRINCIPLE}

Tonometry is a non-invasive technique for the continuos measurement of pressure in closed vessels (blood vessels, uterus, bladder, brain pressure). Figure 1 illustrates the principle of tonometric blood pressure measurement. The blood vessel is pressed flush against the sensor surface until appropriate flattening is achieved. According to Laplace's law, the pressure gradient across the vessel wall is given by:

$$
P_{\text {out }}-P_{\text {in }}=\frac{T}{r}
$$

where Pout and Pin are the pressures outside and inside the vessel, respectively. $T$ is the vessel wall tension, and $r$ is the vessel radius. As can be seen, if the vessel wall is completely flattened against a smooth sensor surface $(r \rightarrow \infty)$, the measured pressure will be equal to the intra-luminal blood pressure $(\Delta P \rightarrow 0)$. Two important requirements regarding this measurement technique are: 1) the hold down force should flatten the vessel wall without creating occlusion, and 2) the pressure sensor diaphragm should be stiffer than the vessel wall. The second requirement is to ensure appropriate flattening and prevent any excessive bending of the vessel wall during the measurement.

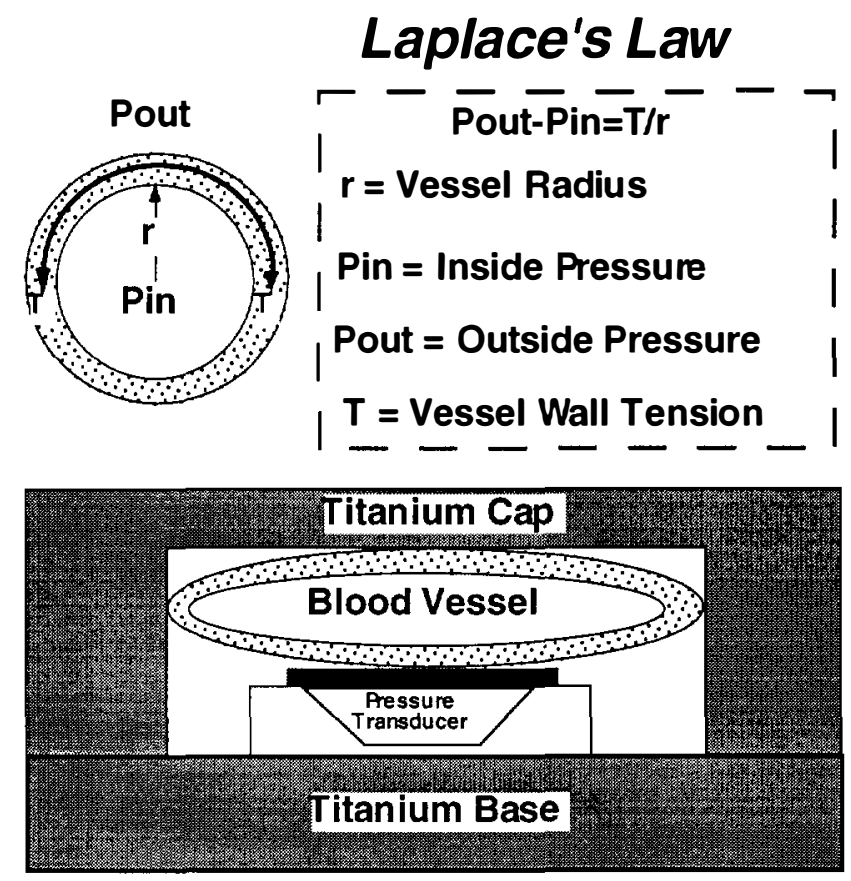

Figure 1: Basic principle of tonometric blood pressure measurement.

\section{MICROSYSTEM STRUCTURE AND DESIGN}

Figure 2 shows the pressure sensor cuff microsystem for blood pressure measurement. The microsystem consists of four 


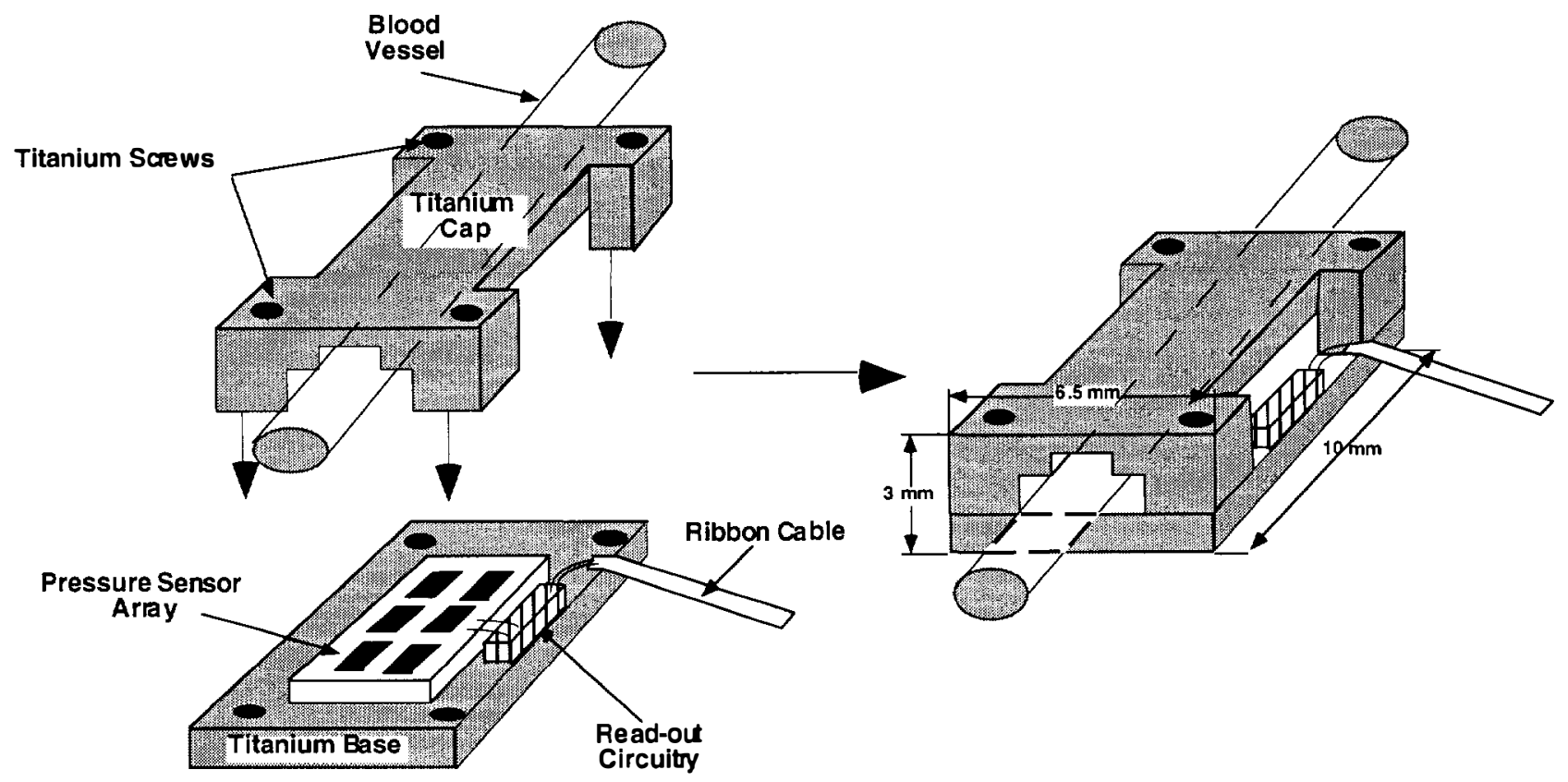

Figure 2: Pressure sensor cuff microsystem for tonometric blood pressure measurement.

major components: 1) a titanium base for supporting the pressure sensor and interface chip, 2) a capacitive pressure sensor array, 3) a switched-capacitor interface chip, and 4) a titanium cap.

The assembly and packaging of the complete system is critical in reducing drift. The sensor and interface chips are mounted on a titanium base with medical grade silicone rubber (NuSil Silicone Technologies, Carpinteria, CA). The blood vessel is subsequently laid on top of the sensor, and a titanium cap is then clamped to the base using four miniature screws (Walter Lorenz Surgical, Jacksonville, Fl.), thus pressing the blood vessel flat against the silicon diaphragm. This assembly technique isolates the pressure sensor from package stress by preventing any direct contact between the transducer and the rest of the package except through the highly compliant silicone rubber adhesive.

The capacitive pressure sensor was designed to measure arterial blood pressure in small mammals. The measurement site was chosen to be rat's descending aorta $(1.5-2 \mathrm{~mm}$ in diameter, $0.1 \mathrm{~mm}$ wall thickness). This location provides sufficient space to fit the pressure sensor cuff without exerting pressure on vital organs. Table 1 summarizes the design parameters for the pressure transducer. An array of three pressure sensors $(1.5 \mathrm{~mm}$ spacing) is located underneath the vessel to increase signal output and improve stability. In order to increase the sensitivity, a long rectangular diaphragm $\left(0.4 \times 1.4 \mathrm{~mm}^{2}\right)$ was designed. The central deflection of a rectangular diaphragm under applied pressure is greater than a circular or an square diaphragm (assuming a width equal to the diameter or side of the circular or square diaphragm), and under large deflections is given by:

$$
\frac{P a^{4}}{E h^{4}}=\frac{1}{\alpha\left(1-v^{2}\right)}\left(\frac{y}{h}\right)+\frac{1}{A^{3}}\left(\frac{y}{h}\right)^{3}+\frac{\sigma a^{2}}{\beta E h^{2}}\left(\frac{y}{h}\right)
$$

where $\mathrm{P}$ is the applied pressure, $\mathrm{y}$ is the central deflection, a and $\mathrm{h}$ are the diaphragm width and thickness, $\mathrm{E}$ and $v$ are Young's modulus and Poisson's ratio of the diaphragm material, $\sigma$ is the internal stress, and finally, $\alpha, \beta$, and $\mathrm{A}$ are geometrical constants depending on the length to width ratio [7]. For the designed diaphragm a pressure of $100 \mathrm{mmHg}$ yields a central deflection of $\sim 2 \mu \mathrm{m}$. An initial (zero differential pressure) gap of $4 \mu \mathrm{m}$ was chosen for the pressure sensor to achieve enough sensitivity ( 3fF/mmHg@ $100 \mathrm{mmHg})$ while providing the required bandwidth $(\sim 50 \mathrm{~Hz})$.

Table 1: Design parameters for the pressure transducer.

\begin{tabular}{|l|l|}
\hline Pressure Range & $0-300 \mathrm{mmHg}$ \\
\hline Resolution & $1 \mathrm{mmHg}$ \\
\hline Base-line Drift & $<1 \mathrm{mmHg} / \mathrm{month}$ \\
\hline Frequency Response & $0-50 \mathrm{~Hz}$ \\
\hline
\end{tabular}

A custom-made switched-capacitor interface chip was designed to readout the sensor output. Figure 3 shows the block diagram of the interface chip. It consists of a charge integrator stage followed by a gain stage. The gain and the offset can be adjusted by laser trimming on-chip capacitors. Figure 4 shows the photograph of the interface capacitive readout chip. Table 2 summarizes important characteristics of the interface chip.

Table 2: Important characteristics of the interface chip.

\begin{tabular}{|l|l|}
\hline Clock Frequency & $1 \mathrm{kHz}$ \\
\hline Supply Voltage & $3 \mathrm{~V}$ \\
\hline Power Consumption & $120 \mu \mathrm{W}$ \\
\hline Trimmable Offset Cap. & $6.6 \mathrm{pF}$ in $1,10,100,500 \mathrm{fF}$ Steps \\
\hline Trimmable Gain & $1-7$ \\
\hline Resolution & $1.4 \mathrm{fF}$ \\
\hline Die Area & $3.3 \mathrm{mmx} 0.64 \mathrm{~mm}$ \\
\hline
\end{tabular}




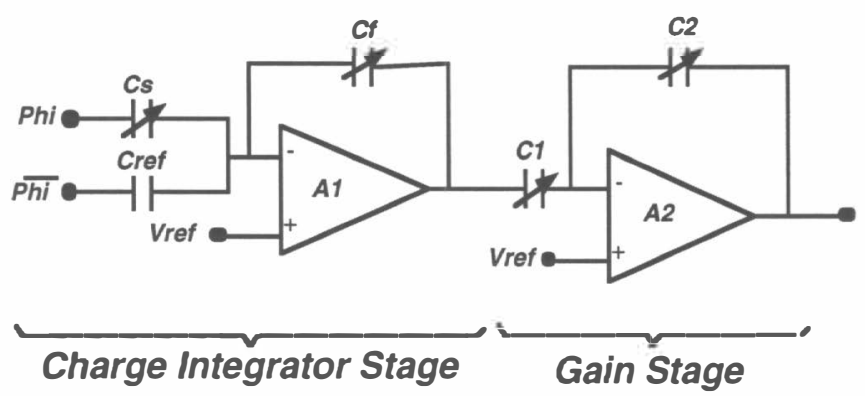

Figure 3: Block diagram of the interface readout circuitry.

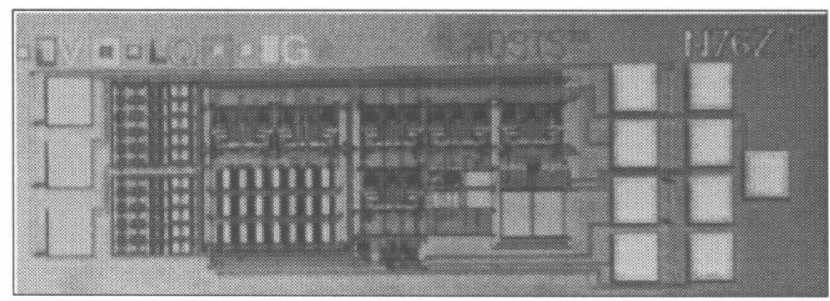

Figure 4: Photograph of an interface capacitive readout chip.

\section{PRESSURE SENSOR FABRICATION}

To form a flat sensor surface, we have developed a new structure and fabrication process (Figure 5), based on the dissolved-wafer process [6]. The capacitive air gap $(\sim 4 \mu \mathrm{m})$ is formed by etching a recess in a glass substrate using $\mathrm{HF} / \mathrm{HNO}_{3} / \mathrm{DI}$ (7:3:10, etch rate $\left.\sim 2.2 \mu \mathrm{m} / \mathrm{min}\right)$. The glass substrate also supports $\mathrm{Ti} / \mathrm{Pt} / \mathrm{Au}(200 \AA / 200 \AA / 1000 \AA)$ lines to form the bottom capacitor plate and interconnect lines. A silicon wafer is patterned for a shallow boron diffusion step using an oxide mask (7500 $)$. A $2.5 \mu \mathrm{m}$ p ++ diffusion is performed to create the pressure sensor diaphragms and bonding areas. This is followed by a thin oxide isolation layer (1000 $\AA$ ) deposition and patterning over the diaphragm areas. The silicon wafer is then electrostatically bonded to the glass wafer and the undoped silicon is dissolved away in EDP to form pressure sensors wherever there is a recess. This technique creates a perfect flat surface, and sealed cavities to prevent fluid accumulation and stiction during the silicon etch. Openings are formed in the silicon using a dry etch $\left(\mathrm{NF}_{3}=10 \mathrm{sccm}\right.$, $\mathrm{O}_{2}=15 \mathrm{sccm}, 200 \mathrm{mT}, 100 \mathrm{~W}$, etch rate $\sim 3000 \AA / \mathrm{min}$ ) to provide access to bonding pads. Figure 6 shows a fabricated sensor array (dimensions $\sim 4.8 \mathrm{~mm} \times 5.7 \mathrm{~mm}$ ).

\section{TEST RESULTS}

In-vitro tests have been performed on the complete cuff using a fluid-filled silastic tube (Scientific Products, Deerfield, Ill.) to mimic a pliable blood vessel. The cavity of the pressure sensor was sealed using a high viscosity, low outgassing epoxy (Master Bond, EP5IND) at atmospheric pressure. It was then attached to the titanium base. A silastic tube was subsequently laid on top of the diaphragm and the titanium cap was screwed to the base. The silastic tube was subsequently pressurized with air using a handheld manometer pump. Figure 7 shows the photograph of an assembled unit, which measures $10 \mathrm{~mm} \times 6.5 \mathrm{~mm} \times 3 \mathrm{~mm}$. Figure 8 shows the measured output

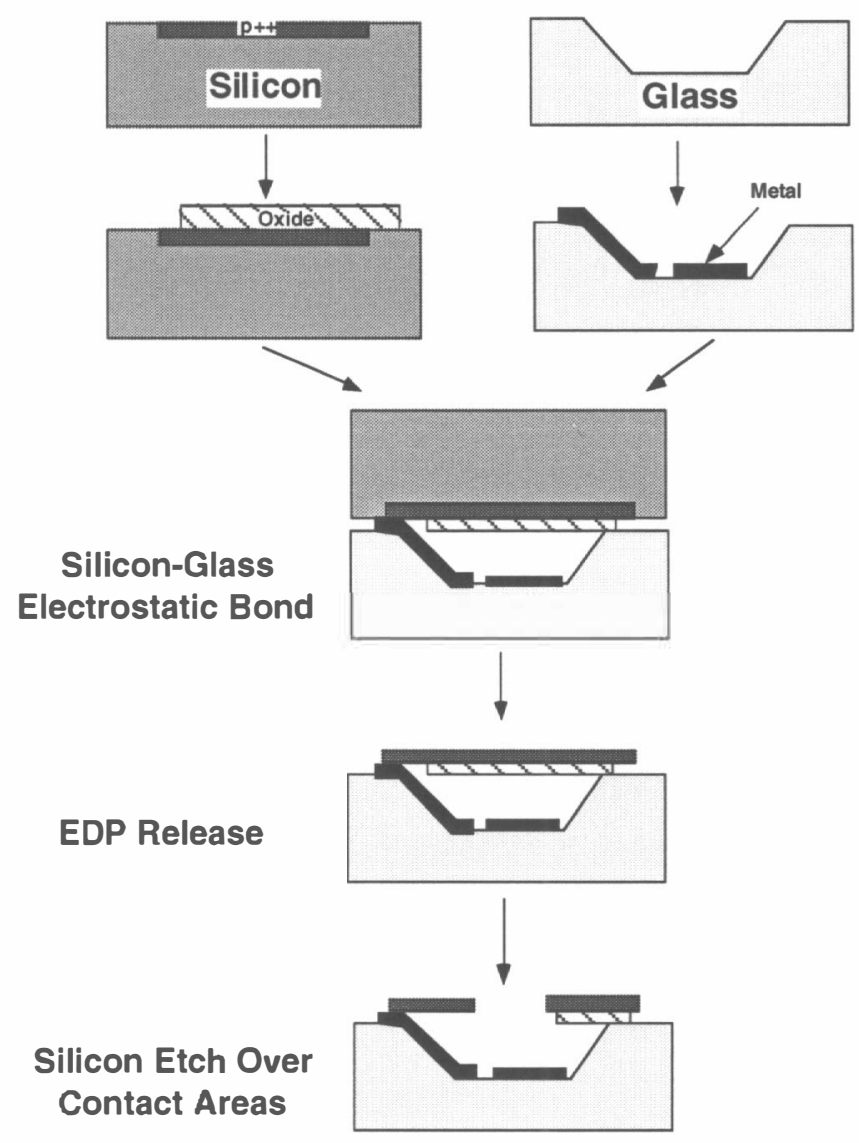

Figure 5: Fabrication process flow for tonometric blood pressure transducer.

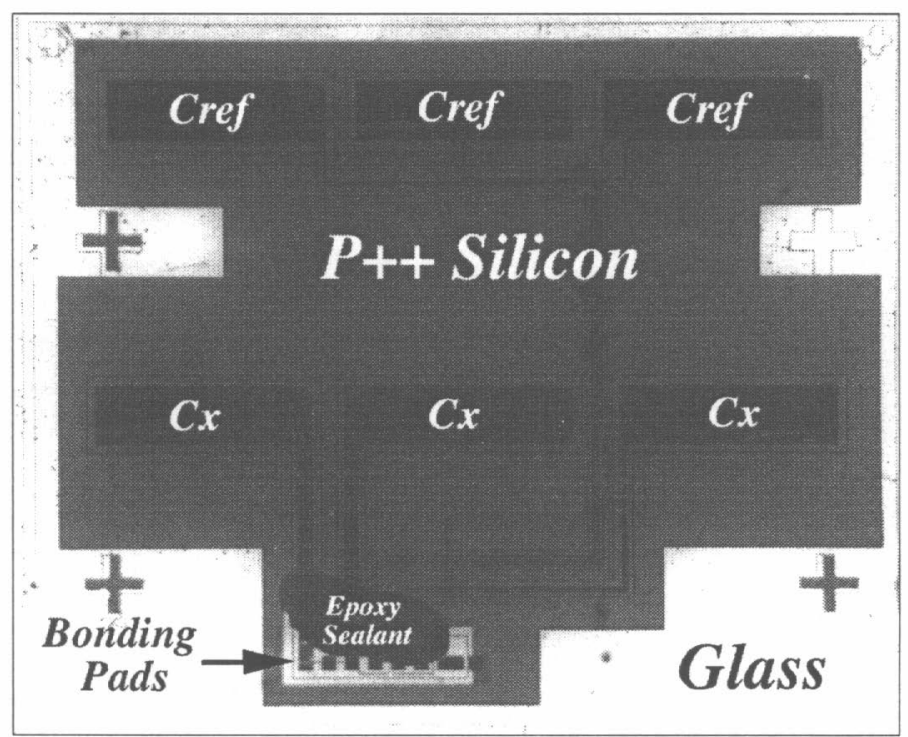

Figure 6: Photograph of a fabricated pressure sensor array. 
voltage as a function of pressure in the silastic tube. A sensitivity of $2.0 \mathrm{mV} / \mathrm{mmHg} @ 100 \mathrm{mmHg}$ and a resolution of $0.5 \mathrm{mmHg}$ has been obtained, as summarized in Table 3. The RMS value of output noise was measured to be $\sim 0.5 \mathrm{mV}$ (peakpeak $\sim 4 \mathrm{mV}$ ). The major source of base-line drift in implantable pressure transducers is the package induced stress, which can be transferred to the transducer diaphragm. By using a compliant silicone rubber to attach the sensor to the package and isolating the sensor from the rest of the assembly, we anticipate to achieve a rather low base-line drift. To test the base-line stability, the pressure sensor output has to be monitored at a fixed temperature and pressure. This requires a controlled test setup to ensure a minimum interference from these variables. We are planning a controlled long term stability test and will report on our results in the future.

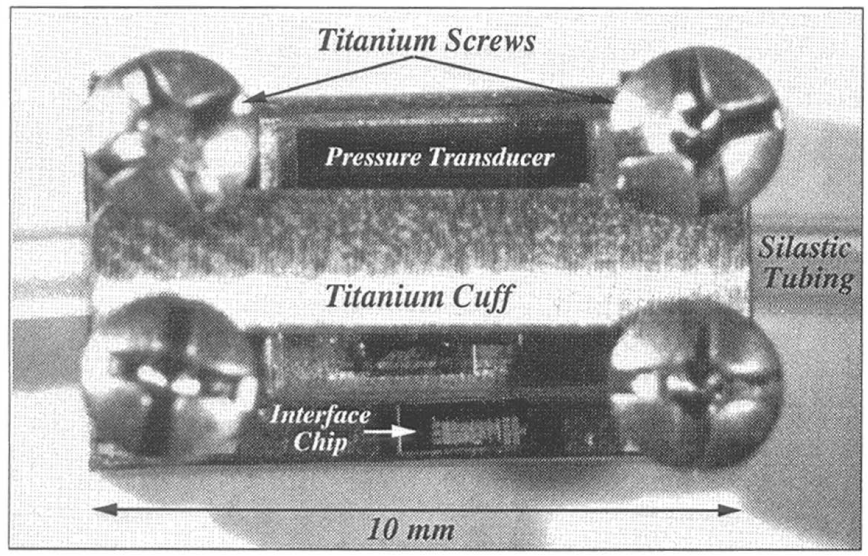

Figure 7: Photograph of an assembled unit showing various components of the microsystem.

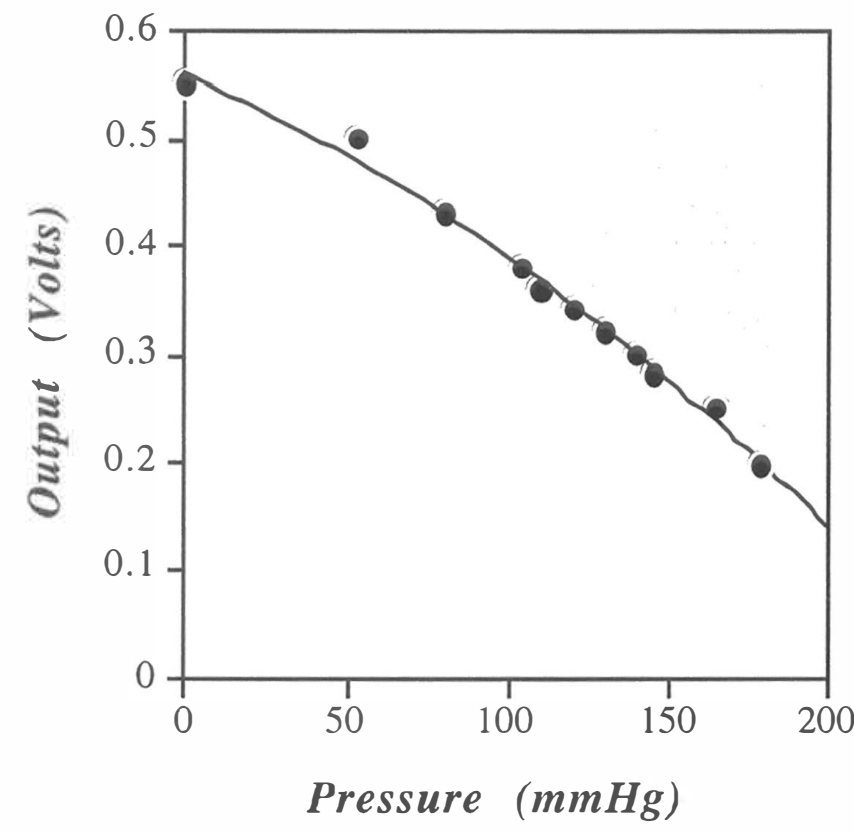

Figure 8: Pressure sensor calibration curve in the arterial blood pressure range with lowest gain setting.
Table 3: Important characteristics of the pressure sensor cuff.

\begin{tabular}{|l|l|}
\hline Co & $1.5 \mathrm{pF}$ \\
\hline$\Delta \mathrm{C} / \Delta \mathrm{P} @ 100 \mathrm{mmHg}$ & $2.8 \mathrm{fF} / \mathrm{mmHg}$ \\
\hline$\Delta \mathrm{V} / \Delta \mathrm{P} @ 100 \mathrm{mmHg}$ & $2.0 \mathrm{mV} / \mathrm{mmHg}$ \\
\hline Interface Chip Noise & $1 \mathrm{mV}, \mathrm{RMS}$ \\
\hline Resolution & $0.5 \mathrm{mmHg}$ \\
\hline Sensor Chip Dimensions & $4.8 \mathrm{~mm} \times 5.7 \mathrm{~mm}$ \\
\hline Ti Cuff Dimensions $(\mathrm{H} \times \mathrm{W} \times \mathrm{L})$ & $3 \mathrm{~mm} \times 6.5 \mathrm{~mm} \times 10 \mathrm{~mm}$ \\
\hline
\end{tabular}

\section{CONCLUSION}

A biomedical microsystem for tonometric blood pressure measurement using micromachining techniques has been developed. This system is the smallest implantable pressure cuff that includes an integrated package, a completely planar capacitive sensor, and an on-board interface circuit (dimensions $\sim 3 \mathrm{~mm} \times 6.5 \mathrm{~mm} \times 10 \mathrm{~mm}$ ).. A titanium base supports a planar pressure transducer and a custom-made switched-capacitor interface chip. The blood vessel is positioned on top of the sensor and a titanium cap is screwed to the base to clamp the vessel. In-vitro tests have shown a sensitivity and resolution of $2.0 \mathrm{mV} / \mathrm{mmHg}$ and $0.5 \mathrm{mmHg}$ at $100 \mathrm{mmHg}$, respectively. The interface chip has a noise floor of $1 \mathrm{mV}$ RMS. Long term baseline stability tests under controlled environment are planed.

\section{ACKNOWLEDGMENTS}

The authors wish to thank Mr. John W. Hines and Dr. Chris. J. Somps of the NASA Ames research center for their support and encouragement. We would also like to thank Walter Lorenz Surgical for their generous help in providing miniature titanium screws. This work is supported by the National Aeronautics and Space Administration (NASA), under grant NAWG-4494.

\section{REFERENCES}

[1] T. P. Broten et al., "Techniques for the Measurement of Arterial Blood Pressure," in Measurement of Cardiovascular Function, J. H. McNeil Ed., CRC Press, 1997.

[2] B. Brockway, et al, "A New Method for Chronic Measurement and Recording of Blood Pressure, Heart Rate and Activity in the Rat via Radio-Telemeter," in Clin. and Exper. Hyper.-Theory and Practice, A13(5), pp. 885-895, 1991.

[3] Konigsberg Instrument, Inc., Biomedical Product Cathalog, April 1994.

[4] G. M. Drzeweicki, J. Melbin, and A. Noordergraaf, "Arterial Tonometry: Review and Analysis," J. Biomechanics, Vol. 16, No. 2, pp. 141-152, 1983.

[5] S. Terry et al., "Silicon Pressure Transducer Arrays for Blood Pressure Measurement," Sensors and Actuators, A21-A23, pp. 1070-1079, 1990.

[6] H. L. Chau, and K. D. Wise, "An Ultraminiature Solid-State Pressure Sensor for a Cardiovascular Catheter," IEEE Trans. Electron Devices, Vol. ED-235, pp. 2355-2362, Dec. 1988.

[7] M. Di Giovanni, Flat and Corrugated Diaphragm Design Handbook, Marcel Dekker, New York, 1982. 